Open Pharmaceutical Sciences Journal
CrossMark
Content list available at: www.benthamopen.com/PHARMSCI
DOI: $10.2174 / 1874844901603010149$

RESEARCH ARTICLE

\title{
Hydroxyl Ethyl Cellulose HHX and Polymethyl Methacrylate Based Site Specific Floating Delivery of Prochlorperazine Maleate
}

\author{
Swati C. Jagdale* and Aleesha B. Randhave \\ Department of Pharmaceutics, MAEER's Maharashtra Institute of Pharmacy, MIT Campus, S. No. 124, Kothrud, Pune \\ 411038, Savitribai Phule Pune University, India
}

Received: March 16, 2016

Revised: May 25, 2016

Accepted: May 27, 2016

\begin{abstract}
:
Background:

Prochlorperazine maleate is a phenothiazine antipsychotic used principally in the treatment of nausea, vomiting and vertigo. Biological half- life of the drug is about 6 to $8 \mathrm{hrs}$ and oral dose is 5 or $10 \mathrm{mg}$ thrice or four times a day. The mean absolute bioavailability for drug is $12.5 \%$. Due to the solubility of drug in acidic $\mathrm{pH}$, it is mainly absorbed from stomach.
\end{abstract}

\section{Objective:}

Site specific oral floating delivery of prochlorperazine maleate will prolong the gastric retention time, increases the drug bioavailability, reduces frequency of administration and can result in better patient compliance.

\section{Method:}

The tablets were prepared by direct compression technique. Floating drug delivery was developed using gas forming agent and release retarding agent i.e. hydroxyethyl cellulose HHX (Natrosol HHX) and polymethyl methacrylate (PMMA). $3^{2}$ full factorial design was used for optimization. Prepared tablets were evaluated for pre and post compression parameters.

\section{Results:}

From the factorial batches it was observed that formulation containing $68.5 \%$ of hydroxyethyl cellulose HHX and $15 \%$ of polymethyl methacrylate had shown a drug release of $91.56 \pm 2.7 \%$ with floating upto 10 hrs following Korsmeyer Peppas release kinetics.

\section{Conclusion:}

In- vivo placebo X-ray study for optimized batch F6 had shown good gastroretention ability for $6 \pm 0.5$ hrs. In-vitro and in-vivo study confirmed the site specific floating delivery for drug.

Keywords: Factorial, Floating, Hydroxyethyl cellulose, Polymethyl methacrylate, Prochlorperazine maleate.

\section{INTRODUCTION}

In the recent years, scientific and technological advancement has been made in the research and development for oral drug delivery system. Oral route is the most convenient and preferred route for drug delivery; may be in a part attributed to its ease of administration, patient compliance, low cost therapy and flexibility in the formulation [1]. Drugs that are easily absorbed from GIT and have short biological half-lives are eliminated quickly from the systemic circulation [2]. Frequent dosing of these drugs is essential to achieve suitable therapeutic activity. However, to over-

\footnotetext{
* Address correspondence to this author at the Department of Pharmaceutics, MAEER's Maharashtra Institute of Pharmacy, MIT Campus, Pune, (MS), 411038, India; Tel: +91-9881478118; E-mails: jadgaleswati@rediffmail.com; swati.jagdale@mippune.edu.in
} 
come this limitation, the development of oral sustained/controlled release formulation is an attempt to release the drug slowly in the systemic circulation for a longer period of time. After oral administration, such drug delivery would be retained in stomach and would release the drug in a controlled manner, so that the drug could be released continuously to its absorption site in GIT. However, oral sustained-controlled release systems, mainly suffer from two limitations i.e. short gastric retention time (GRT) and unpredictable short gastric emptying time (GET), which could result in incomplete drug release from the dosage form, leading to diminished efficacy of administered dose. To formulate a sitespecific orally administered controlled release dosage form, prolonged gastric retention will mainly improve bioavailability, increase the duration of drug release and reduce drug waste [3].

Gastro retentive drug delivery systems are the systems that are retained in stomach for a longer period of time and thereby improve bioavailability of drug. Floating drug delivery system is one of the techniques that are currently used to formulate a successful gastro retentive drug delivery system. Floating systems or hydrodynamically controlled systems are low density systems that have buoyancy to float over the gastric contents and remain buoyant in the stomach without affecting the gastric emptying rate for a prolonged period of time. While this system is floating on the gastric content, the drug is slowly released at the desired rate from the system. After release of drug, the residual system is emptied from the stomach. This result in an increased gastric retention time (GRT) and better control for the fluctuation in the plasma drug concentrations [4 - 6].

Prochlorperazine maleate is a phenothiazine antipsychotic used in the treatment of nausea, vomiting and vertigo. Its antiemetic effects are attributed to dopamine blockade in the chemoreceptor trigger zone. For treatment of nausea and vomiting, 5 or $10 \mathrm{mg}$ thrice or four times daily dose of prochlorperazine maleate is given orally. It has mean absolute bioavailability of $12.5 \%$ due to extensive metabolism, principally in liver. It has biological half life of 6 to 8 hrs. Due to solubility of drug in acidic $\mathrm{pH}$, drug is absorbed in stomach; therefore the drug should be retained in the stomach for longer period of time to achieve the desired effect. Due to short biological half life, drugs usually require multiple dosing to achieve and maintain therapeutic level. Literature survey had indicated that, work has been carried out on mouth dissolving tablet, sustained release matrix tablet and transdermal patch for prochlorperazine maleate [7 - 9]. Prochlorperazine maleate was chosen as drug candidate for the present research work since it possesses all the ideal characteristics that a drug must have in formulating gastro retentive floating drug delivery system. The properties include, low molecular weight (606.10), low absolute bioavailability (12.5\%) and short biological half life (6 to 8 hrs) $[10-12]$.

The main aim was to achieve control release for the drug by retaining the drug in stomach for a longer period of time as well as to reduce frequency of dosing. The objective for the present work was to enhance the bioavailability and to prevent first pass metabolism of the drug. The present work therefore deals with design, formulation, evaluation and optimization of site specific floating delivery of prochlorperazine maleate using polymers, hydroxyethyl cellulose HHX (Natrosol HHX) and polymethyl methacrylate (PMMA) [13 - 15].

\section{MATERIALS AND METHODS}

\subsection{Materials}

Prochlorperazine maleate was a gift sample from Mehta Pharmaceutical Industries, Mumbai. Hydroxyl ethyl cellulose HHX (Natrosol HHX) was provided as gift sample from Colorcon Asia Pvt. Ltd, Mumbai. Polymethyl Methacrylate (PMMA), magnesium stearate, talc, sodium bicarbonate, citric acid and dicalcium phosphate was purchased from Analab fine chemicals, Mumbai.

\subsection{Experimental Work}

\subsubsection{Characterization of Prochlorperazine Maleate:}

\subsubsection{Physical Characterization}

Pure drug was observed visually for its appearance and color.

\subsubsection{Melting Point}

The melting point of drug was determined using melting point apparatus (Labin). 


\subsubsection{FTIR (Fourier Transform Spectroscopic Studies) Spectroscopic Study}

The drug excipient interaction was determined using FTIR Spectrophotometer (Varian 640 IR).

\subsubsection{Stability of Srug in Media}

The stability of drug in $0.1 \mathrm{~N} \mathrm{HCl}$ was observed for $24 \mathrm{hrs}$ by dissolving the drug in media. The solution was scanned immediately and at intervals till $24 \mathrm{hrs}$ at $\lambda_{\max }$ of the drug using UV Spectrophotometer (UB Varian carry 100 scan) [16].

\subsubsection{UV Spectroscopic Study}

UV Spectroscopic analysis of the drug was carried out using UV spectrophotometer for drug concentrations in range of $1-5 \mu \mathrm{g} / \mathrm{mL}$ in $0.1 \mathrm{~N} \mathrm{HCl}$.

\subsubsection{Differential Scanning Calorimetry (DSC) Study}

DSC of drug, polymer and optimized formulation was studied using differential scanning calorimeter (DSC 60, Shimadzu Corporation, Japan). Heating was carried out at a temperature of $50^{\circ}-300^{\circ} \mathrm{C}$ with rate of $10^{\circ} \mathrm{C}$ per minute in nitrogen atmosphere.

\subsubsection{Compatibility Study of Drug, Polymers and Excipient}

Drug alone and drug with polymer (Hydroxyl ethyl cellulose HHX and PMMA) were mixed in 1:1 ratio. This was kept in the stability chamber (Thermo Lab Scientific Equipments, 90/90/130 litres) for one month at $30^{\circ} \mathrm{C} \pm 2{ }^{\circ} \mathrm{C} / 65 \%$ $\mathrm{RH} \pm 5 \% \mathrm{RH}$ and $40 \pm 2^{\circ} \mathrm{C} / 75 \pm 5 \% \mathrm{RH}$ according to ICH guidelines to check the stability. At the end of one month, samples were removed and examined for compatibility study using FTIR, DSC and UV spectrophotometer [17].

\subsubsection{Preparation of Prochlorperazine Maleate Tablet}

Effervescent floating tablets containing prochlorperazine maleate were prepared by direct compression technique. Different concentrations of polymer Hydroxyl ethyl cellulose HHX and PMMA were tested along with sodium bicarbonate and citric acid (Table 1). All ingredients were weighed accurately. Except magnesium stearate all other ingredients were uniformly mixed in powder form in polythene bag. After ten minutes of mixing, magnesium stearate was added as post lubricant and further mixed for additional 2-3 minutes. The tablets were compressed using eight station rotary tablet compression machine (mini press II ' $\mathrm{D}$ ' tooling- Rimek model) and $9 \mathrm{~mm}$ round, flat and plain punch. The weight of tablet was kept constant for all the formulations i.e. $200 \mathrm{mg}$.

Table 1. Preliminary trial batches (T1-T9).

\begin{tabular}{|c|c|c|c|c|c|c|c|c|c|}
\hline Ingredients (mg) & T1 & T2 & T3 & T4 & T5 & T6 & T7 & T8 & T9 \\
\hline Hydroxyl ethyl cellulose HHX & 170 & - & - & 170 & 170 & 140 & 110 & 140 & 110 \\
\hline Crosspovidone (Kollidone) & - & 170 & - & - & - & - & - & - & - \\
\hline PMMA & - & - & 170 & - & - & 30 & 60 & - & - \\
\hline Methacrylic acid & - & - & - & 8 & - & - & - & 46 & 60 \\
\hline Sodium bicarbonate & 6 & 6 & 6 & - & 8 & 8 & 8 & - & 8 \\
\hline Citric acid & 2 & 2 & 2 & - & 8 & 8 & 8 & - & 8 \\
\hline Magnesium stearate & 1 & 1 & 1 & 1 & 1 & 1 & 1 & 1 & 1 \\
\hline Talc & 1 & 1 & 1 & 1 & 1 & 1 & 1 & 1 & 1 \\
\hline Dicalcium phosphate & 10 & 10 & 10 & 10 & 2 & 2 & 2 & 2 & 2 \\
\hline Prochlorperazine maleate & 10 & 10 & 10 & 10 & 10 & 10 & 10 & 10 & 10 \\
\hline
\end{tabular}

Total weight of tablet $=200 \mathrm{mg}$

\subsubsection{Preliminary Trial Batches}

At preliminary stage different trial batches were prepared for floating tablet using single polymer as well as with combination of polymers (Hydroxyl ethyl cellulose HHX and PMMA). Sodium bicarbonate and citric acid were incorporated as gas forming agent. Concentration of gas forming agent was initially finalized. Then, concentration of polymers individually and in combination was predicted for factorial design as shown in Table 1. Final weight of the tablet was adjusted to $200 \mathrm{mg}$ using dicalcium phosphate as filler. Same procedure was applied for all the powder blend. Formulations were evaluated for tablet weight, hardness, buoyancy time and floating time. 


\subsubsection{Factorial Design}

On the basis of evaluation of trial batches concentration of polymer was decided. $3^{2}$ full factorial design was applied to establish a relationship in between independent and dependent variables using software program design expert version 9.0.3.1. $3^{2}$ level full factorial design includes 9 full factorial design points; according to the model total 9 experiments were conducted $[18,19]$. This design involves dependent and independent variables. The concentration of Hydroxyl ethyl cellulose HHX (X1) and PMMA (X2) was considered as the independent variables. The dependent variables were Y1; Percent drug release, Y2; Hardness, Y3; Swelling index, Y4; Floating time. The three concentrations were such decided that the difference in between the three consecutive levels is the same.

\subsubsection{Formulation of Factorial Batches}

The coded levels and the actual concentration of the variables used in formulation containing Hydroxyl ethyl cellulose HHX and PMMA are as shown in Table 2. The formulations were prepared as shown in Table 3.

Table 2. Coded level for the actual level of variable (F1-F9).

\begin{tabular}{|c|c|c|}
\hline Variable used & \multicolumn{2}{|c|}{ Coded levels } \\
\hline & -1 & 0 \\
\hline Hydroxyl ethyl cellulose HHX & $67 \%$ & $68.5 \%$ \\
\hline PMMA & $12 \%$ & $13.5 \%$ \\
\hline
\end{tabular}

Table 3. Formulation of factorial batch (F1-F9).

\begin{tabular}{|c|c|c|c|c|c|c|c|c|}
\hline \multirow[t]{2}{*}{ Batch } & \multicolumn{8}{|c|}{ Ingredients (mg) } \\
\hline & Variable (1) & Variable (2) & PM & Mg stearate & Talc & $\mathrm{NaHCO}_{3}$ & Citric acid & DCP \\
\hline F1 & 134 & 24 & 10 & 1 & 1 & 8 & 8 & 14 \\
\hline $\mathrm{F} 2$ & 134 & 27 & 10 & 1 & 1 & 8 & 8 & 11 \\
\hline F3 & 134 & 30 & 10 & 1 & 1 & 8 & 8 & 8 \\
\hline F4 & 137 & 24 & 10 & 1 & 1 & 8 & 8 & 11 \\
\hline F5 & 137 & 27 & 10 & 1 & 1 & 8 & 8 & 8 \\
\hline F6 & 137 & 30 & 10 & 1 & 1 & 8 & 8 & 5 \\
\hline F7 & 140 & 24 & 10 & 1 & 1 & 8 & 8 & 8 \\
\hline F8 & 140 & 27 & 10 & 1 & 1 & 8 & 8 & 5 \\
\hline F9 & 140 & 30 & 10 & 1 & 1 & 8 & 8 & 2 \\
\hline
\end{tabular}

Total weight of tablet: $200 \mathrm{mg}$

Where; Variable $1=$ Hydroxyl ethyl cellulose $\mathrm{HHX}$, Variable $2=$ Polymethyl Methacrylate $(\mathrm{PMMA}), \mathrm{PM}=\mathrm{Prochlorperazine} \mathrm{maleate,} \mathrm{NaHCO}_{3}=$ Sodium bicarbonate, DCP $=$ Dicalcium phosphate, $\mathrm{Mg}$ stearate $=$ Magnesium stearate

\subsubsection{Evaluation of Prochlorperazine Maleate Floating Tablet}

Evaluation of floating tablet was performed in two steps i.e. pre-compression and post-compression $[1-6,18,19]$.

\subsubsection{Pre-Compression Evaluation}

Pre-compression parameter study involved evaluation of powder blend for following parameters:

Angle of repose was determined by funnel method.

Bulk density and Tapped density was determined using digital bulk density apparatus (Bio Techno Lab, Make Lab HOSP)

Compressibility index was calculated using eq. 1;

Compressibility index $(\%)=\rho t-\rho o / \rho t \times 100$ (eq. 1)

Where $\rho o$ is bulk density and $\rho t$ is tapped density

Hausner's ratio was calculated using equation eq. 2;

Hausner's ratio $=$ Tapped density/ Bulk density (eq. 2)

Post compression evaluation 
Shape and size of tablet was determined by visual observation. Thickness and diameter of tablet were measured using a calibrated vernier caliper.

Hardness was determined using Monsanto hardness tester.

Friability test was carried out for twenty tablets using Roche Friabilator.

Weight variation: Twenty tablets were selected randomly from each batch and weighed individually to check for weight variation.

Drug content: Ten tablets were weighed individually and powdered. The powder equivalent to $10 \mathrm{mg}$ of prochlorperazine maleate was transferred to a $100 \mathrm{~mL}$ of volumetric flask containing $0.1 \mathrm{~N} \mathrm{HCl}$, was mixed and filtered. $1 \mathrm{~mL}$ of this filtrate was diluted with $10 \mathrm{~mL}$ of $0.1 \mathrm{~N} \mathrm{HCl}$. The sample was analyzed for drug content using UV spectrophotometer at $\lambda_{\max }$ of the drug. Calculation for the drug content was carried out using line equation from calibration curve.

Buoyancy study/ Floating test:In- vitro floating behavior of the tablet was studied using USP dissolution test apparatus type II and dissolution tester (Electro Lab, TDT 08L). The apparatus was filled with $900 \mathrm{~mL} \mathrm{of} 0.1 \mathrm{~N} \mathrm{HCl}$ and temperature was maintained at $37 \pm 0.5^{\circ} \mathrm{C}$. The speed of rotation was maintained at $50 \mathrm{rpm}$. The time taken by the tablet to rise onto the surface of dissolution medium was determined as buoyancy lag time or floating time.

Swelling index: Swelling index of the tablet was calculated in order to find out swelling ability of tablet. For calculating the swelling index, previously weighed tablet were placed in the $100 \mathrm{~mL}$ beaker containing $0.1 \mathrm{~N} H \mathrm{HCl}$. The tablet were removed at the time interval of $1 \mathrm{hr}$ up to $8 \mathrm{hrs}$, placed on filter paper to dry and weighed again. Swelling index was calculated using eq.3;

Swelling index $=\left(\mathrm{w}_{\mathrm{t}}-\mathrm{w}\right) / \mathrm{w} \times 100$ (eq. 3)

Where $\mathrm{w}_{\mathrm{t}}=$ Final weight of tablet at time ' $\mathrm{t}$ ', $\mathrm{w}=$ Initial weight of tablet

In- vitro dissolution study: In-vitro dissolution study were carried out in $0.1 \mathrm{~N} \mathrm{HCl}(900 \mathrm{~mL})$ at $37 \pm 0.5^{\circ} \mathrm{C}$ using USP dissolution apparatus type II, dissolution tester (Electro Lab, TDT 08L). The speed of rotation was set at $50 \mathrm{rpm}$. $10 \mathrm{~mL}$ of sample was withdrawn from the dissolution apparatus after every half an hr upto 10 hrs. The samples were removed and replaced with fresh dissolution medium $(0.1 \mathrm{~N} \mathrm{HCl})$. Drug release was determined by scanning the samples removed at $\lambda_{\max }$ of the drug using UV spectrophotometer. fluid.

In- vitro dissolution study for F6 and F9 having highest drug releases were then carried out in simulated gastric

\subsubsection{Statistical Analysis of Data [20, 21]}

Kinetics of drug release: PCP Disso V3 software was used to study the kinetics of drug release and to determine best fit model.

Full factorial design of experiment: Design Expert, version 9.0.3.1 software program was used.

Similarity factor study

Similarity factor (f2) provides simple way to compare dissolution data. According to USA FDA guidance, f2 value in between 50-100 indicates equivalence in dissolution profile. Market contains only mouth dissolving tablet. Similarity factor study was carried out using BIT software between marketed tablet of Prochlorperazine maleate (Stemetil MD 5) and optimized formulation F6 was used as test product. Similarity factor was determined using data obtained from drug release study.

\subsubsection{Stability Study}

Stability study was carried out for the optimized batch $\mathrm{F} 6$ at long term $\left(30^{\circ} \mathrm{C} \pm 2{ }^{\circ} \mathrm{C} / 65 \% \mathrm{RH} \pm 5 \% \mathrm{RH}\right)$ and accelerated condition $\left(40 \pm 2^{\circ} \mathrm{C} / 75 \pm 5 \% \mathrm{RH}\right)$ over three months period according to $\mathrm{ICH}$ guidelines using stability chamber (Thermo Lab Scientific Equipments). At the end of three months and at monthly time interval, the tablets were withdrawn from the stability chamber and were examined for thickness, diameter, hardness, drug content, floating lag time and in-vitro drug release. 


\subsubsection{In- vivo X-Ray Placebo Study}

In- vivo X-ray placebo study was performed by selecting the optimized batch from the factorial batches. Procedure for in-vivo placebo study was performed as per world medical association guidelines and Helsinki ethical principles. Three healthy human volunteers, with an age of 20-25 years and 56-70 kg body weight participated in in-vivo placebo study. The informed consent of each human volunteer was taken before participation. Study was carried out under supervision of expert radiologist and physician. Study does not involve any blood sampling. The aim of the study was to locate the position of tablet in GIT and to study floating behavior for the tablet. Taking into consideration the human behavior present study was restricted for $6 \mathrm{hrs}$. X-ray imaging technique was used only to monitor the position of the tablet throughout gastrointestinal system. Prochlorperazine maleate was replaced with radio opaque agent, barium sulphate. X-ray study of optimized placebo tablet F6 (contained barium sulphate $10 \mathrm{mg}$, Hydroxyl ethyl cellulose HHX $137 \mathrm{mg}$, PMMA $30 \mathrm{mg}$, magnesium stearate $1 \mathrm{mg}$, talc $1 \mathrm{mg}$, sodium bicarbonate 8mg, citric acid 8mg, dicalcium phosphate $5 \mathrm{mg}$ ) was performed on three healthy human volunteers using X-ray generating unit. Prepared tablets were administered to every subject in fed condition. Radiographs were taken at initial and at 2 and $6 \mathrm{hrs}$ [22].

\section{RESULTS AND DISCUSSION}

\subsection{Characterization of Prochlorperazine Maleate}

\subsubsection{Physical Characterization}

Powder was white or pale yellow, crystalline powder, practically odorless.

\subsubsection{Melting Point}

The melting point of drug was found to be $226^{\circ} \mathrm{C}$, the reported melting point of drug is $228^{\circ} \mathrm{C}$. This indicated that the drug is in pure form $[10,11]$.

\subsubsection{FTIR Spectroscopic Study}

FTIR spectrum (Fig. 1) of prochlorperazine maleate showed intense peaks at $3299 \mathrm{~cm}^{-1}$ for hydroxyl groups of acid, 1735 and $1663 \mathrm{~cm}^{-1}$ for carbonyl group of acid, aromatic and aliphatic C-H stretch were observed around $2970 \mathrm{~cm}^{-1}$, $2953 \mathrm{~cm}^{-1}, 2938 \mathrm{~cm}^{-1}$ and $2917 \mathrm{~cm}^{-1}$, respectively This matches with the standard reports proving the purity of the drug sample [23].
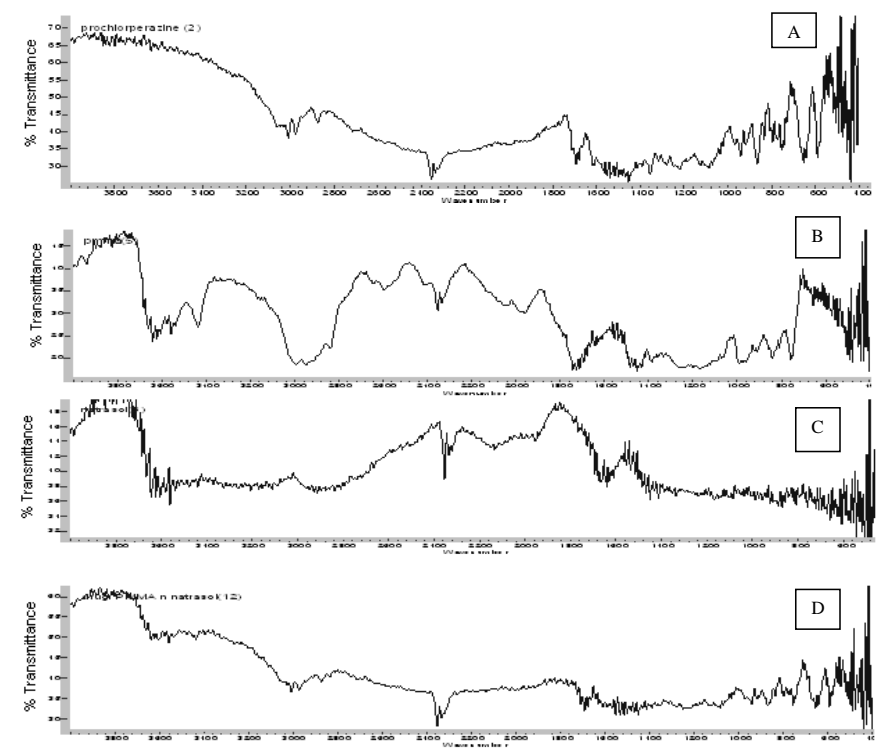

Fig. (1). IR Spectrum of (A) Prochlorperazine maleate, (B) PMMA, (C) Hydroxyl ethyl cellulose HHX, and (D) Optimized batch F6. 


\subsubsection{Stability of Drug in Media}

UV absorption of prochlorperazine maleate in $0.1 \mathrm{~N} \mathrm{HCl}$ showed $\lambda_{\text {max }}$ at $254.20 \mathrm{~nm}$. Absorbance for concentrations $1-5 \mu \mathrm{g} / \mathrm{mL}$ of prochlorperazine maleate was recorded in $0.1 \mathrm{~N} \mathrm{HCl}$. Line equation for the calibration curve was found to be; $y=0.050 x-0.0025\left(R^{2}=0.999\right)$ (eq. 4)

The graph obtained for absorbance versus concentration was found to be linear. Thus, the drug obeys Beer'sLamberts law in the range of $1-5 \mu \mathrm{g} / \mathrm{mL}$

The drug was found to be stable in $0.1 \mathrm{~N} \mathrm{HCl}$ based on the results of UV spectroscopic study as there was no significant change in absorbance and $\lambda_{\text {max }}$ value.

\subsubsection{Differential Scanning Calorimetry (DSC) Study}

DSC spectrum for pure drug is as shown in Fig. 2(A). DSC thermographs showed a sharp peak at $212.48^{\circ} \mathrm{C}$. Hydroxyl ethyl cellulose HHX showed wide peak nearly ranging from $55^{\circ} \mathrm{C}$ up to $110^{\circ} \mathrm{C}$. The center point was around $88.35^{\circ} \mathrm{C}$ (Fig. 2C). Optimized formulation $\mathrm{F} 6$ showed peaks at $88.37^{\circ} \mathrm{C}, 116.58^{\circ} \mathrm{C}, 158.42^{\circ} \mathrm{C}$ and $197.46^{\circ} \mathrm{C}$, respectively (Fig. 2D). From the thermographs (Fig. 2) it was observed that there was no shift in the peak of Hydroxyl ethyl cellulose HHX even in the formulation F6, but there was a shift observed in the peak of the drug in the formulation F6. The shift in the DSC peak for the drug was mainly due to polymer interlinking and engulfing of drug in the polymer matrix.

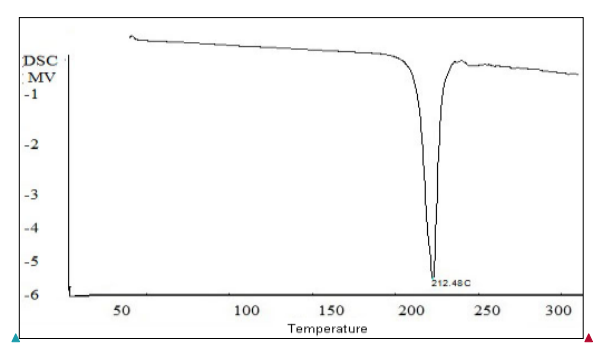

A

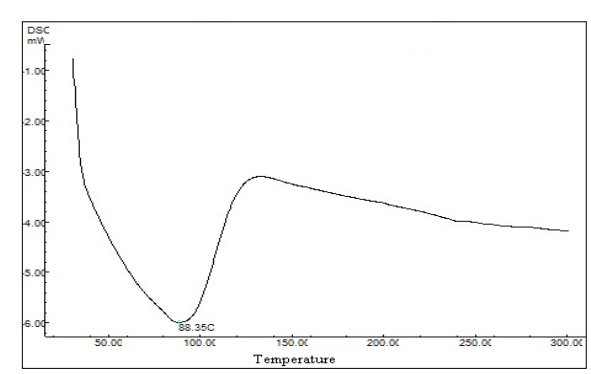

$\mathrm{C}$

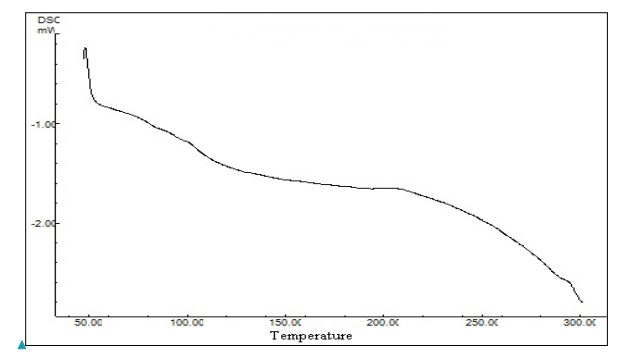

B

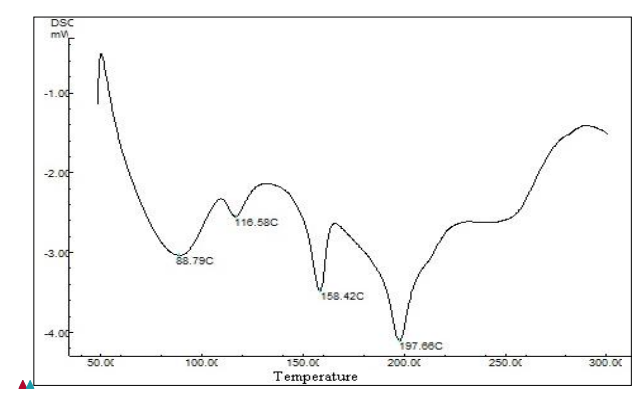

D

Fig. (2). DSC spectrum of; (A) Prochlorperazine maleate, (B) PMMA, (C) Hydroxyl ethyl cellulose HHX (Natrosol HHX), (D) Optimized batch F6.

\subsection{Compatibility Study}

\subsubsection{Fourier Transform Infrared Spectroscopy Study}

FTIR spectrum of drug, polymers and formulation F6 is shown in Fig. (1). The IR scan (Fig. 1) showed prominent peaks for various active groups present in pure drug such as $3299 \mathrm{~cm}^{-1}$ for hydroxyl groups of acid, 1735 and $1663 \mathrm{~cm}^{-1}$ for carbonyl group of acid, aromatic and aliphatic C-H stretch were observed around 2970, 2953, 2938 and $2917 \mathrm{~cm}^{-1}$, respectively. It was observed that there were no significant differences in the peaks for active groups in the drug in combination with polymer and in optimized formulation. All this study revealed that the drug is in pure state even in formulation without any chemical interaction with polymers and excipients. 


\subsubsection{UV Spectroscopic Study}

As shown in Fig. (3), UV spectroscopic study for drug, drug with polymers and in formulation showed that there was no change in the $\lambda_{\max }$ of drug. This confirmed that there were no interactions between the drug with polymers and drug with excipients.

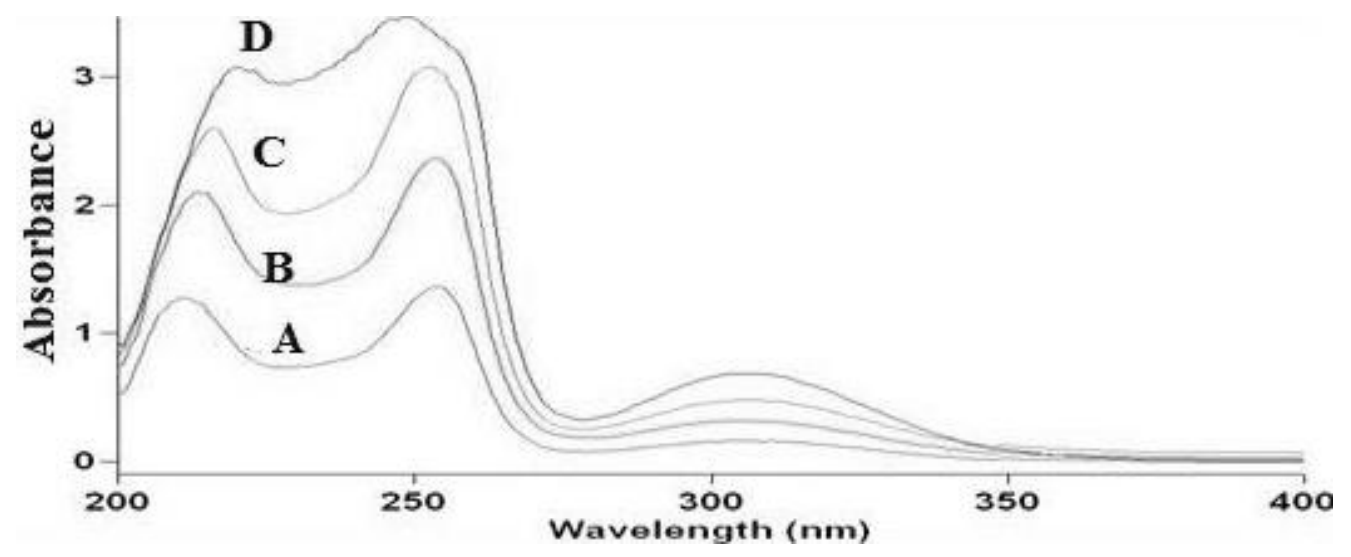

Fig. (3). UV spectra of (A) Prochlorperazine maleate, (B) drug and Hydroxyl ethyl cellulose HHX, (C) drug and PMMA, (D) Optimized batch F6.

Results of FTIR and UV spectroscopic study confirmed the stability of drug with polymer and excipients.

\subsection{Preliminary Trial Batches}

All the trial batches (T1-T9) were evaluated for tablet weight, hardness, buoyancy lag time and floating time. The results were found in the range as; tablet weight $(200 \pm 2.5 \mathrm{mg})$, hardness $\left(4-6.5 \mathrm{~kg} / \mathrm{cm}^{2}\right)$, buoyancy lag time $(90-600$ seconds) and floating time (1- $10 \mathrm{hrs})$.

In the preliminary trial batches, sodium bicarbonate (3\%) and citric acid (1\%) were initially used for testing floating ability of tablet. The tablets had shown floating property but was settled down after 5-6 hrs. Therefore, the concentration of gas forming agents in the tablets was increased as $4 \%$ of sodium bicarbonate and $4 \%$ of citric acid. This had shown floating of tablets for $10 \mathrm{hrs}$. When the total polymer weight in the floating tablet contains hydroxyl ethyl cellulose HHX, the tablet floated but did not show proper release characteristics. When replaced with $100 \%$ Kollidone the tablet showed floating but dissolved after 2 hrs. When replaced with $100 \%$ of PMMA initially tablet showed floating but broke within $1 \mathrm{hr}$ due to insufficient hardness. Tablet containing 100\% of hydroxyl ethyl cellulose HHX and low concentration of methacrylic acid without gas forming agents, did not show floating property. When the concentration of methacrylic acid was increased and gas forming agents were incorporated, the tablet floated immediately but settled after $3 \mathrm{hrs}$.

At the preliminary stage all the polymers individually failed to achieve sufficient hardness and floating properties. Therefore, to achieve hardness and floating properties combination of polymer were used. The concentration of Hydroxyl ethyl cellulose HHX was varied from 55\% to $85 \%$ and PMMA was varied from $15 \%$ to $30 \%$ to achieve the desired effect. The concentrations of Hydroxyl ethyl cellulose HHX (70\%) and PMMA (15\%) were finalized to be considered for further study design, since it showed hardness $6.5 \mathrm{~kg} / \mathrm{cm}^{2}$, buoyancy time of 90 seconds and floating ability for $10 \mathrm{hrs}$. Moreover, this batch was used to carry out experimental design.

\subsection{Evaluation of Factorial Batches}

Based on the preliminary trial batches factorial batches, $3^{2}$ full factorial was designed. Different batches were prepared and evaluated for pre-compression and post-compression parameters.

\subsubsection{Pre-Compression Evaluation}

Pre-compression parameters for powder blend mixtures of floating tablets of prochlorperazine maleate (F1-F9) showed results within specified limits for angle of repose $\left(25-30^{\circ} \mathrm{C}\right)$, compressibility index $(11-15 \%)$ and Hausner's ratio (1.12-1.18). These values indicated that all the powder blend mixtures showed good flow properties. 


\subsubsection{Post-Compression Evaluation}

Results for thickness, diameter, drug content, friability, hardness, buoyancy lag time and weight variation for factorial batches are as shown in Table 4. Variation in polymer concentration drastically changed hardness and swelling index which further showed major effect on buoyancy time and percent drug release.

Table 4. Results for post compression parameters of factorial batches F1-F9.

\begin{tabular}{|c|c|c|c|c|c|c|c|}
\hline $\begin{array}{l}\text { Batch } \\
\text { code }\end{array}$ & Thickness (mm) & Diameter $(\mathbf{m m})$ & Drug content (\%) & Friability (\%) & $\begin{array}{c}\text { Hardness } \\
\left(\mathrm{kg} / \mathrm{cm}^{2}\right)\end{array}$ & $\begin{array}{c}\text { Buoyancy lag } \\
\text { time (sec) }\end{array}$ & Weight variation (mg) \\
\hline $\mathrm{F} 1$ & $2 \pm 1.2$ & $9 \pm 1.4$ & $97.2 \pm 1.3$ & $0.55 \pm 1.2$ & $7.5 \pm 0.5$ & $600 \pm 5$ & $200.79 \pm 1.3$ \\
\hline F2 & $2 \pm 1.4$ & $9 \pm 1.1$ & $98.1 \pm 1.5$ & $0.49 \pm 1.1$ & $6 \pm 0.8$ & $900 \pm 10$ & $199.54 \pm 1.1$ \\
\hline $\mathrm{F} 3$ & $2 \pm 1.5$ & $9 \pm 1.7$ & $97.94 \pm 1.8$ & $0.51 \pm 1.5$ & $6.5 \pm 0.5$ & $780 \pm 10$ & $201.92 \pm 1.9$ \\
\hline $\mathrm{F} 4$ & $2 \pm 1.6$ & $9 \pm 1.9$ & $97.17 \pm 1.2$ & $0.57 \pm 1.4$ & $6 \pm 0.4$ & $660 \pm 5$ & $200.04 \pm 1.2$ \\
\hline F5 & $2 \pm 1.1$ & $9 \pm 1.3$ & $98.91 \pm 1.4$ & $0.46 \pm 1.1$ & $5.5 \pm 0.5$ & $5 \pm 3$ & $200.98 \pm 1.4$ \\
\hline F6 & $2 \pm 1.3$ & $9 \pm 1.5$ & $99.52 \pm 1.9$ & $0.41 \pm 1.3$ & $7 \pm 0.5$ & $3 \pm 2$ & $199.65 \pm 1.5$ \\
\hline F7 & $2 \pm 1.7$ & $9 \pm 1.2$ & $97.58 \pm 1.1$ & $0.53 \pm 1.2$ & $7.5 \pm 0.8$ & $15 \pm 5$ & $200.12 \pm 1.3$ \\
\hline $\mathrm{F} 8$ & $2 \pm 1.9$ & $9 \pm 1.6$ & $98.22 \pm 1.7$ & $0.48 \pm 1.5$ & $5.5 \pm 0.4$ & $20 \pm 10$ & $198.12 \pm 1.3$ \\
\hline F9 & $2 \pm 1$ & $9 \pm 1.8$ & $99.21 \pm 1.6$ & $0.43 \pm 1.5$ & $6.5 \pm 0.5$ & $10 \pm 5$ & $200.13 \pm 1.2$ \\
\hline
\end{tabular}

Batches F1-F4 showed buoyancy time between 600-900 seconds. F1-F4 failed due to high buoyancy time and so was not considered for further study.

\subsection{Swelling Indices for F1-F9 Factorial Batches}

Swelling indices for F1-F9 factorial batches are as shown in Fig. (4). Swelling was a vital factor to ensure buoyancy and drug dissolution of matrix tablet. When the tablet was placed in the dissolution media, hydrophilic swelling agent formed a thick gel upon hydration. Hydroxyl ethyl cellulose HHX is a water soluble polymer which formed hydrogen bonds with water and got hydrated. Such solutions are pseudoplastic that is, they vary in viscosity depending on the amount of shear stress applied. Hydroxyl ethyl cellulose HHX (Natrosol) has thickening and water binding property which is specially used for jellies and ointments. This showed higher degree of swelling due to more water uptake and lower degree of erosion due to polymer contraction. PMMA which is a crystalline polymer has shown less degree of swelling due to less water uptake and higher degree of erosion due to polymer relaxation. Gelling properties of the polymers were responsible for the maintenance of matrix integrity and slow release of drug from the formulation. From the results, it was observed that swelling increases with time because the polymer gradually absorbs water due to its hydrophilic nature. From the swelling indices of all the batches it was observed that, swelling increases with increase in concentration of polymers. Thus, it was found that the concentration of polymers showed major influence on swelling properties for all the batches. Highest swelling index was observed for batch F9, which contained highest concentration of polymers. Lowest swelling index was observed for batch F1 which contained lowest concentration of polymers. From literature data, it was observed that use of HPMC increases the extent of gel formation in the diffusion layer and also had retarded the release of drug. Whereas in combination of carbopol moderate sustained release profile was obtained. This was mainly based on the swelling property of the polymer [7].

\subsubsection{In -Vitro Dissolution Study}

F1 to F9 had different concentration of Hydroxyl ethyl cellulose HHX and PMMA. Since both the polymers had swelling properties, all the formulation had shown different release characteristics. In- vitro dissolution profiles for formulations (F1-F9) are as shown in the Fig. (5). Out of all the nine formulations F1-F4 were not considered while optimizing the best batch. These four formulations when placed in dissolution medium had shown difficulty in floating and have settled down in 2-3 hrs. This may be due to the presence of high concentration of dicalcium phosphate which was used as filler and had density greater than the gastric fluid i.e. $2.89 \mathrm{~g} / \mathrm{cm}^{3}$. Also, formulations F1-F4 did not comply with the standard of percent drug release for extended release tablet [24]. Formulations F5- F9 when placed in dissolution medium floated and complied with the standards of percent drug release for extended release tablet. Formulations F6 and F9 floated for $10 \mathrm{hrs}$ with maximum drug release of $86.88 \pm 1.9 \%$ and $84.04 \pm 2.1 \%$. 


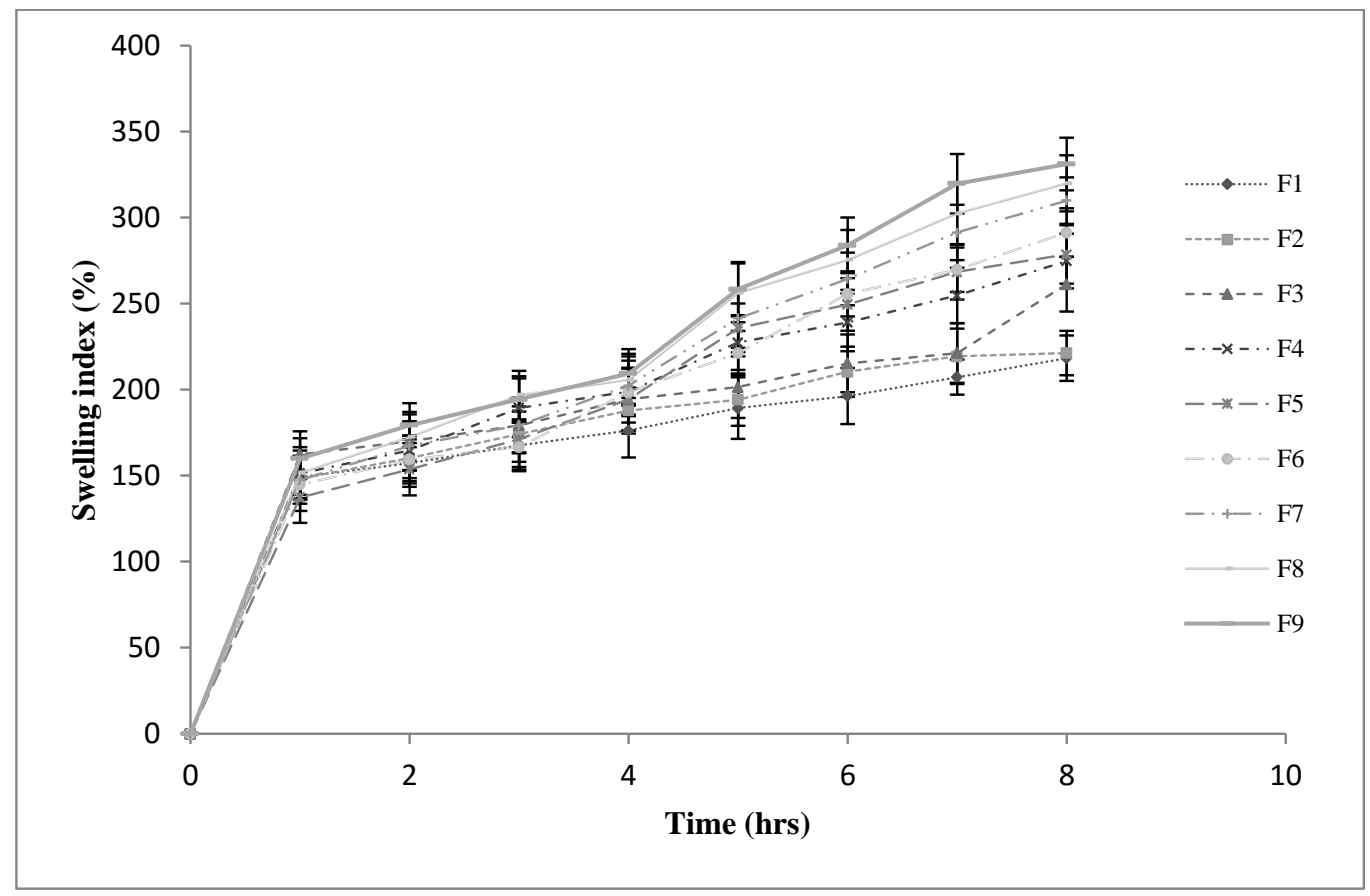

Fig. (4). Results for \% Swelling indices for factorial batches F1-F9.

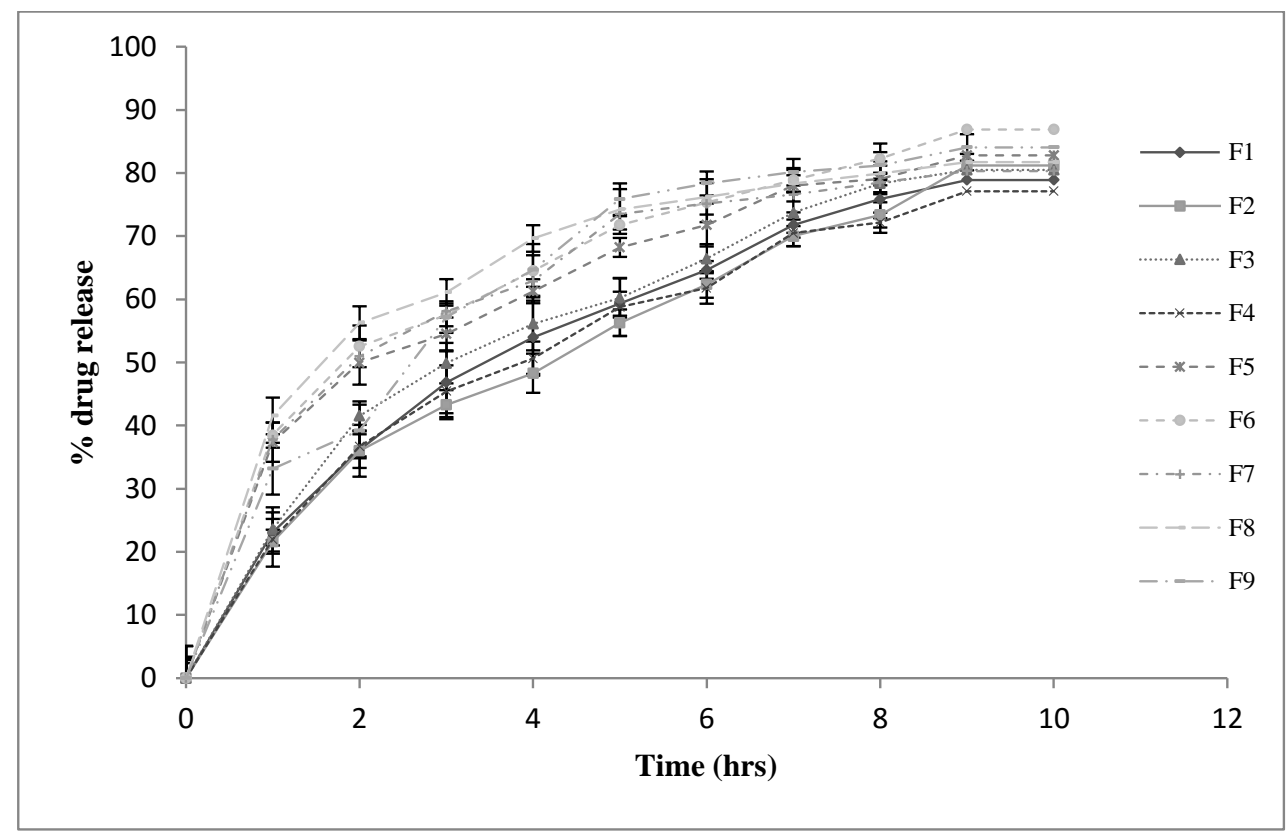

Fig. (5). \% drug release profile for factorial batches F1-F9.

Therefore, in- vitro dissolution study was carried out for formulations F6 and F9 in simulated gastric media and the release graph is shown in Fig. (6) [25]. F6 showed highest percent drug release of $91.56 \pm 2.7 \%$, floated for 10 hrs and hence served as the objective of the study. Different grades of polymethyl methacrylate are commercially available to achieve the $\mathrm{pH}$ dependent drug release for enhancing the bioavailability and minimizing the side effects. They are applied as film coat, enteric coat, sustaining the drug release and as a tablet matrix. Similar kind of results has been demonstrated for different drugs using combination with polymethyl methacrylate which is reported in a review by 
Gupta et al. [26]. Hydroxyethyl Cellulose (HEC) can be useful in control of time-related symptoms which need timecontrolled or site-specific delivery in the gastrointestinal tract. This has been proved for diltiazem hydrochloride tablet [27]. It was observed that lag time can be optionally controlled by selecting HEC with a proper viscosity and/or by changing the amount of HEC for the tablet.

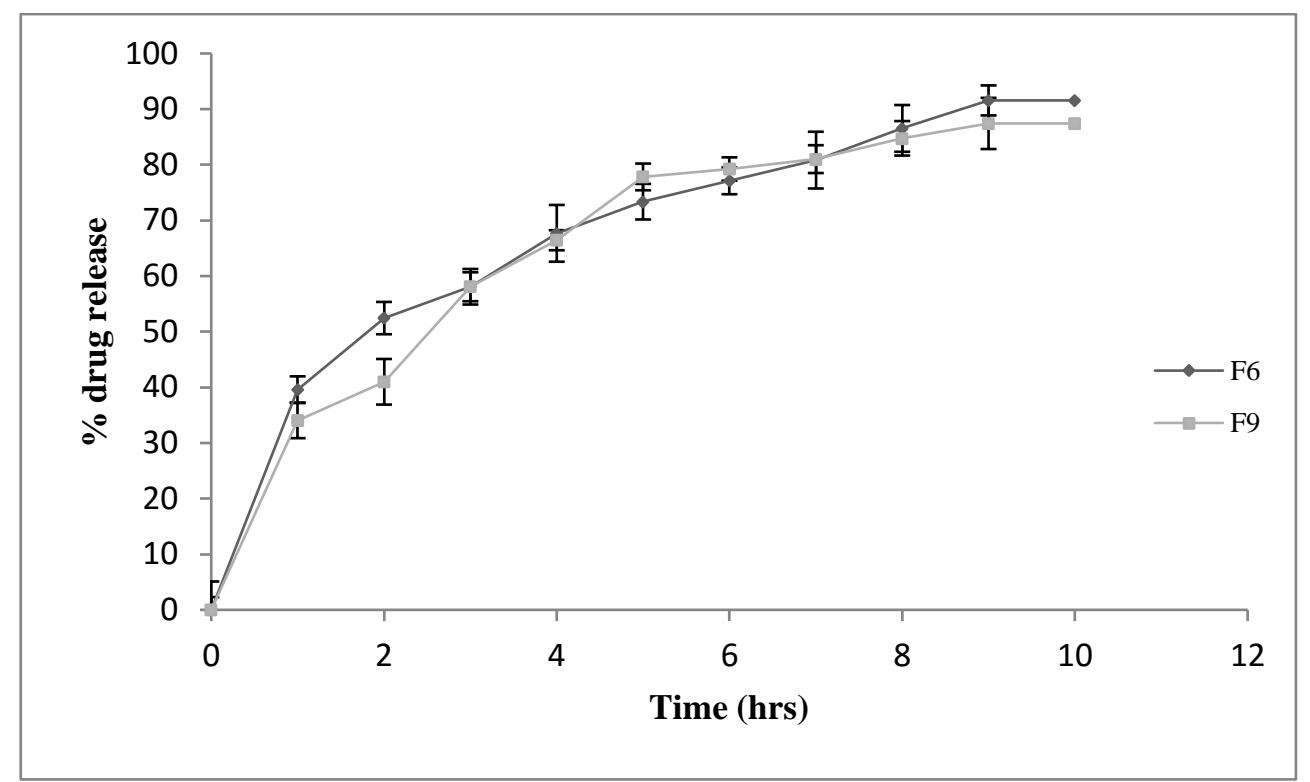

Fig. (6). Comparative \% drug release profile of formulations F6 and F9 in simulated gastric fluid.

\subsection{Statistical Analysis of Data}

\subsubsection{Kinetics of Drug Release}

The best fit model was found out based on the R value. As shown in Table 5, formulations F1-F4 showed matrix as best fit model and formulations F5-F9 showed Korsmeyer Peppas as best fit model. Optimized batch F6 showed Korsmeyer Peppas as best fit model based on R value. As the release exponent (n) showed value (0.3848) which was less than 0.5 the drug followed Fickian diffusion transport mechanism due to swelling of the polymer in controlled manner [28].

Table 5. Kinetics of drug release (F1-F9).

\begin{tabular}{|c|c|c|c|c|c|c|c|c|}
\hline \multirow[t]{2}{*}{ Batch code } & \multirow{2}{*}{\begin{tabular}{|c|} 
Zero order \\
(R)
\end{tabular}} & \multirow{2}{*}{\begin{tabular}{|l|}
$1^{\text {st }}$ order \\
(R)
\end{tabular}} & \multirow{2}{*}{\begin{tabular}{|c|} 
Matrix \\
(R)
\end{tabular}} & \multicolumn{3}{|c|}{ Korsmeyer Peppas } & \multirow{2}{*}{\begin{tabular}{|c|} 
Hixson Crowell \\
(R)
\end{tabular}} & \multirow[t]{2}{*}{ Best fit model } \\
\hline & & & & $\mathbf{R}$ & $\mathbf{n}$ & $\mathbf{K}$ & & \\
\hline F1 & 0.8697 & \begin{tabular}{|l|l}
0.9876 \\
\end{tabular} & 0.9979 & 0.9932 & 0.5097 & 3.2509 & 0.9662 & Matrix \\
\hline $\mathrm{F} 2$ & 0.8993 & 0.9866 & 0.9956 & 0.9902 & 0.4948 & 3.3529 & 0.9754 & Matrix \\
\hline F3 & 0.8562 & 0.9863 & 0.9970 & 0.9895 & 0.4983 & 3.5648 & 0.9634 & Matrix \\
\hline $\mathrm{F} 4$ & 0.8903 & \begin{tabular}{|l|}
0.9858 \\
\end{tabular} & 0.9864 & 0.8484 & 0.6639 & 1.2789 & 0.9675 & Matrix \\
\hline F5 & 0.6427 & 0.9512 & 0.9785 & 0.9946 & 0.3887 & 7.3404 & 0.8924 & Peppas \\
\hline F6 & 0.6340 & 0.9622 & 0.9781 & 0.9963 & 0.3848 & 7.7955 & 0.9041 & Peppas \\
\hline F7 & 0.4926 & 0.8985 & 0.9572 & 0.9928 & 0.3721 & 8.2630 & 0.8185 & Peppas \\
\hline $\mathrm{F} 8$ & 0.3970 & \begin{tabular}{|l|}
0.8752 \\
\end{tabular} & 0.9414 & 0.9808 & 0.3791 & 8.2327 & 0.7822 & Peppas \\
\hline F9 & 0.7393 & 0.9539 & 0.9802 & 0.9833 & 0.4315 & 5.8909 & 0.9120 & Peppas \\
\hline
\end{tabular}

$\mathrm{R}^{2}$ is Correlation coefficient; $\mathrm{n}$ is Diffusion exponent; $\mathrm{k}$ is Rate constant.

\subsection{Response Surface Plots}

Response surface methodology was used as experimental design to determine the effect of independent variables on dependent variables. This was studied using Design expert software version 9.0.3.1. Application of experimental design showed non-significant effect on the formulation with respect to hardness. Effect of independent variables on drug release and swelling index is shown in eqs. 5 and 6;

$\%$ Drug release at $6 \mathrm{hrs}=+70.11+6.00 \mathrm{~A}+2.83 \mathrm{~B}$ (eq. 5 ) 
Swelling index at $8 \mathrm{hrs}=+278.53+43.35 \mathrm{~A}+13.48 \mathrm{~B}$ (eq. 6)

Where A = Hydroxyl ethyl cellulose HHX ; B = PMMA

From the above polynomial equations, response surface and contour plots of the respective responses were generated as shown in Figs. (7 and 8), respectively. Statistical optimization was carried out by the software which suggested that linear model was followed by both the responses.

From eq. 5 and Fig. (7) for percentage of drug release at $6 \mathrm{hrs,} \mathrm{it} \mathrm{was} \mathrm{found} \mathrm{that} \mathrm{Hydroxyl} \mathrm{ethyl} \mathrm{cellulose} \mathrm{HHX} \mathrm{and}$ PMMA have significant effect on the drug release. The response was increased with the individual polymer concentration. Both the polymers showed positive effect on the drug release profile. Hydroxyl ethyl cellulose HHX showed greater effect on drug release as compared to PMMA. The p-value for percent drug release at 6 hrs was found to be 0.0060 which was less than 0.0500 which indicated that the model was highly significant. At 6 hrs the drug release from the formulation was found to be significant since the drug release of the factorial batches complied with the standards of percent drug release for modified release tablet.
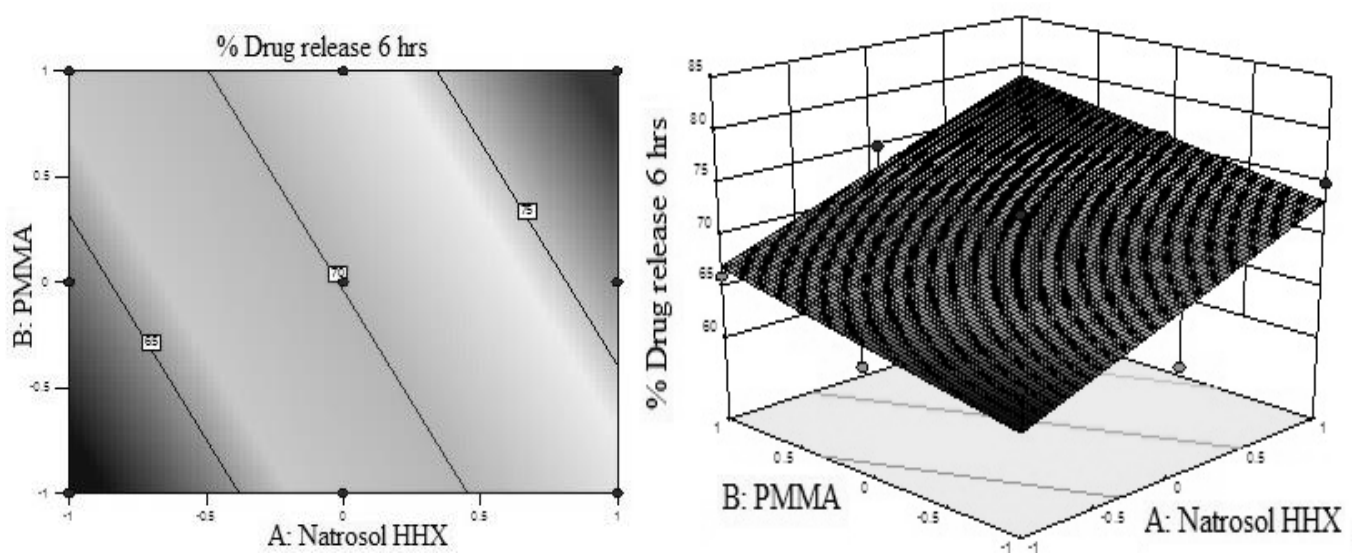

Fig. (7). (A) Contour plot and (B) response surface plot showed relationship in between \% drug release at 6 hrs and levels of polymers (Hydroxyl ethyl cellulose HHX and PMMA).

From eq. 6 and Fig. (8) for swelling index at 8 hrs it was found that both the polymers individually have positive effect on swelling index. The swelling increased with the increase in the concentration of individual polymer. Hydroxyl ethyl cellulose HHX had shown greater effect on swelling index as compared to PMMA. The p-value for swelling index at $8 \mathrm{hrs}$ was 0.0001 which was less than 0.0500 , indicating that the model was highly significant. At 8 hrs the swelling was found to be critical which further controlled the release of drug in sustained manner. This receives confirmation from mathematical model (ANNOVA) generated for response indicated in Table 6.
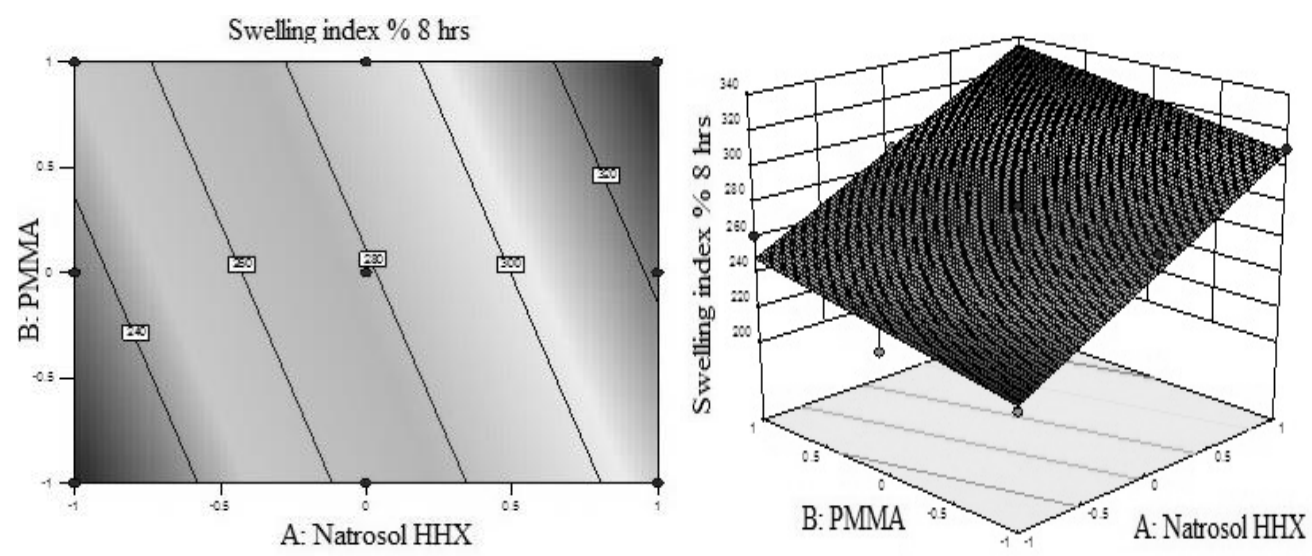

Fig. (8). (A) Contour plot and (B) response surface plot showed relationship in between \% swelling index at 8 hrs and levels of polymers (Hydroxyl ethyl cellulose HHX and PMMA). 
Table 6. ANNOVA used to generate statistical models (F1-F9).

\begin{tabular}{|c|c|c|c|c|c|c|c|}
\hline Response model & Sum of squares & df & Mean square & F value & P value & $\mathbf{R}^{2}$ & Adequate precision \\
\hline \%Drug release at 6 hrs & 264.17 & 2 & 132.08 & 13.50 & 0.0060 & 0.8181 & 9.781 \\
\hline Swelling index (\%) at 8 hrs & 12367.87 & 2 & 6183.94 & 76.86 & 0.0001 & 0.9624 & 21.950 \\
\hline
\end{tabular}

\section{Validation of statistical model}

After statistical analysis by the design expert software, the experimental values were found to be very close to the predicted values as indicated in Table 7; hence the model was successfully validated.

Table 7. Comparison of predicted and actual values.

\begin{tabular}{|c|c|c|c|c|c|}
\hline \multirow[t]{3}{*}{ Polymers } & \multirow[t]{3}{*}{ Coded levels } & \multirow[t]{3}{*}{ Actual levels (\%) } & Response & $\begin{array}{c}\% \text { drug release } \\
\text { at } 6 \mathrm{hrs}\end{array}$ & $\%$ Swelling index at $8 \mathrm{hrs}$ \\
\hline & & & Predicted value & 72.94 & 292.01 \\
\hline & & & Observed value & 75.32 & 281.73 \\
\hline Hydroxyl ethyl cellulose HHX & 0 & $68.5 \%$ & Standard deviation & 3.12 & 8.9698 \\
\hline PMMA & 1 & $15 \%$ & Standard error mean & 1.648 & 4.7275 \\
\hline
\end{tabular}

\subsection{Similarity Factor Study}

Factor $\mathrm{f} 1$ was obtained as 99 and factor $\mathrm{f} 2$ as 10 . Factor $\mathrm{f} 2$ was found to be less than 50 . This confirmed no similarity in the drug release between the test and the marketed formulation, as marketed formulation was immediately release in mouth dissolving tablet and the optimized batch F6 was sustained release tablet.

\subsection{Stability Study}

The result for evaluated parameters of the optimized batch F6 containing $68.5 \%$ of Hydroxyl ethyl cellulose HHX and $15 \%$ of PMMA in accelerated stability conditions had shown thickness $(2 \pm 1.5 \mathrm{~mm})$, diameter $(9 \pm 1.5 \mathrm{~mm})$, hardness $\left(6.5 \pm 0.5 \mathrm{~kg} / \mathrm{cm}^{2}\right)$, drug content $(98.54 \pm 5 \%)$, floating lag time $(20 \pm 5$ seconds) and percentage drug release $(93.56 \pm 5 \%)$. It was observed that there was no significant change in the evaluated parameters at the start of the study and after completion of the study.

\subsection{In-Vivo X-Ray Placebo Study}

The radiograph taken at $2 \mathrm{hrs}$ indicated the buoyancy of tablet in case of volunteer in fed state. The main aim of the study was to prove the floating ability of the formulation in body. The duration of tablet in stomach was monitored by radiographs for $6 \mathrm{hrs}$. The study may be extended upto $10 \mathrm{hrs}$ but considering the human conditions it was restricted to 6 hrs only. It was observed that (Fig. 9) the optimized tablet (F6) floated and did not adhere in stomach. The tablet remains in floating condition in stomach for $6 \pm 0.5 \mathrm{hrs}$ that is duration till the study is carried out. Present study confirms the floating ability (Gastro retention) and presence of dosage form in stomach that indicated presence of drug at the site required for the absorption.
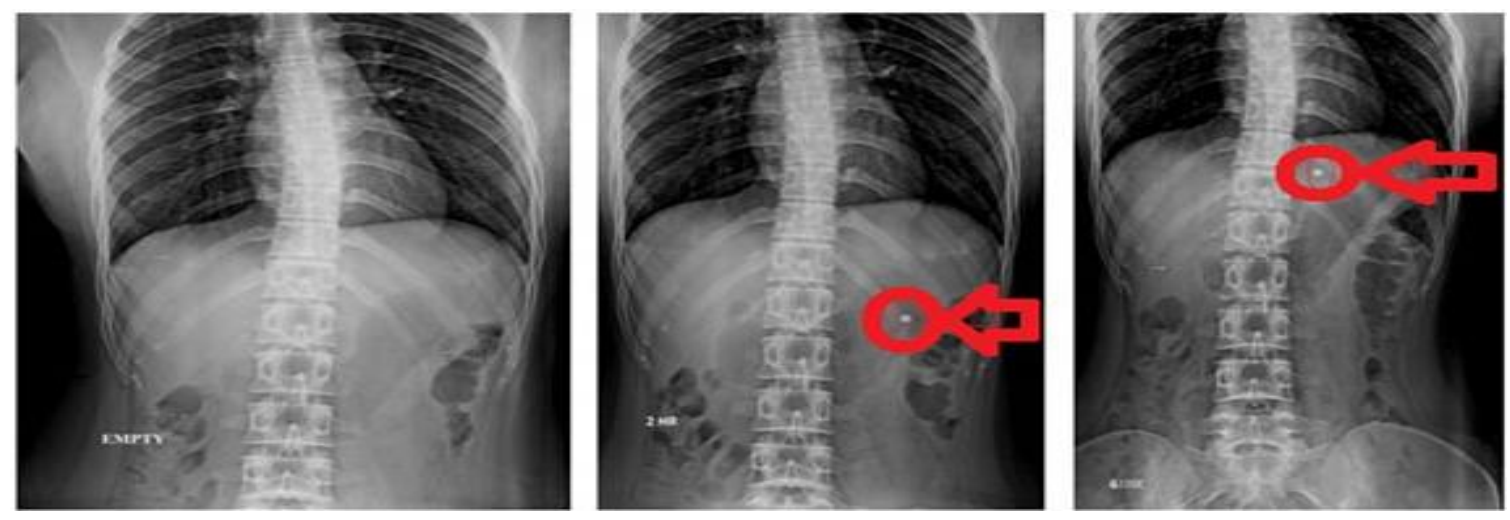

Fig. (9). X-ray of Optimized batch F6 (Hydroxyl ethyl cellulose HHX and PMMA) at 2 hrs and 6 hrs. 


\section{CONCLUSION}

Optimized site specific floating delivery of Prochlorperazine maleate with controlled release profile is obtained using Hydroxyl ethyl cellulose HHX and PMMA. Based on the performance with respect to buoyancy lag time, floating time and release characteristics, formulation F6 containing 68.5\% of Hydroxyl ethyl cellulose HHX and 15\% of PMMA was selected as the best formulation. F6 showed buoyancy time of $3 \pm 2$ seconds, floating time of 10 hrs and drug release of $91.56 \pm 2.7 \%$ in in-vitro study. Formulation F6 showed a sustained drug release throughout its floatation period. Invivo X-ray placebo study showed gastro retention, indicating successful gastro retentive floating drug delivery system of prochlorperazine maleate.

\section{LIST OF ABBREVIATIONS}

$\begin{array}{lll}\text { DCP } & = & \text { Dicalcium phosphate } \\ \text { Hydroxyl ethyl cellulose HHX } & = & \text { Hydroxyethyl cellulose HHX } \\ \text { Mg-stearate } & = & \text { Magnesium stearate } \\ \text { NaHCO }_{3} & = & \text { Sodium bicarbonate } \\ \text { PM } & = & \text { Prochlorperazine maleate } \\ \text { PMMA } & = & \text { Polymethyl methacrylate }\end{array}$

\section{CONFLICT OF INTEREST}

The authors confirm that this article content has no conflict of interest.

\section{ACKNOWLEDGEMENTS}

The authors are thankful to Mehta Pharmaceutical Industries, Mumbai, for providing gift sample of Prochlorperazine maleate, Colorcon Asia Pvt. Ltd, Mumbai for providing gift sample of polymer (Hydroxyl ethyl cellulose HHX). The authors are also thankful to SKN General Hospital and Medical College, Narhe, Pune, who provided the facilities to carry out the in vivo X-ray placebo study of the developed dosage form. The authors are also thankful to Principal Dr. B. S. Kuchekar and Management of MAEER's Maharashtra Institute of Pharmacy, Pune for providing all the support and facilities to carry out the research work.

\section{REFERENCES}

[1] Dixit N. Floating drug delivery system. J Curr Pharm Res 2011; 7(1): 6-20.

[2] Dwivedi S, Kumar V. Floating drug delivery systems: a concept of gastroretentive dosage form. Int J Res Pharm Biomed Sci 2011; 2(4): 1413-26.

[3] Nayak AK, Maji R, Das B. Gastroretentive drug delivery system: a review. Asian J Pharm Clin Res 2010; 3(1): 2-10.

[4] Dahiya A, Rohilla A, Rohilla S, Khan M. Gastroretentive dosage forms: an approach to oral controlled drug delivery systems. Int J Pharm Biol Arch 2011; 2(2): 615-20.

[5] Shukla S, Patidar A, Agarwal S, Choukse R. A review on: recent advancements of stomach specific floating drug delivery system. Int J Pharm Biol Arch 2011; 2(6): 1561-8.

[6] Jamil F, Sharma S, Vishwakarma P, Singh L. Review on stomach specific drug delivery system: development and evaluation. Int. J Res Pharm Biomed Sci 2011; 2(4): 1427-33.

[7] Venkatesh ND, Sankar S, Meyyanathan SN, Elango K. Design and development of prochlorperazine maleate sustained release tablet: influence of hydrophilic polymers on the release rate and in vitro evaluation. Int J Pharm Sci Nanotech 2010; 3(2): 965-77.

[8] Vaja DN, Patel MM, Joshi VT, Patel JM. Design development and characterization of orally disintegrating tablet of prochlorperazine maleate. J Chem Pharm Res 2010; 2(5): 307-12.

[9] Ganju E, Ganju K, Pathak AK. Formulation and evaluation of transdermal patch of prochlorperazine maleate for hyperemesis gravidarum. Int J Res Pharm Chem 2011; 1(4): 1115-8.

[10] Available from: http://www.drugbank.ca/search?button=\&query=prochlorperazine + malate\&search_type $=$ drugs\&utf $8=\%$ E $2 \% 9 C \% 93$

[11] Available from: http://www.drugs.com/search.php?searchterm=prochlorperazine+maleate

[12] Indian Pharmacopoeia, Vol I and II , The Indian Pharmacopoeia commission. $7^{\text {th }}$ ed. Ghaziabad 2014.

[13] Rowe RC, Sheskey PJ, Quinn ME, Cook WG, Fenton ME. Handbook of Pharmaceutical Excipients. $7^{\text {th }}$ ed. London: PhP Pharmaceutical Press 2012.

[14] Patel J, Patel B, Parmar K, Patel M. Formulation and evaluation of delayed release tablets using hydroxyethyl cellulose as a gel forming 
matrix. IJP's J. Pharm Cosmet 2011; 1(2): 94-103.

[15] Srinivas P, Sreeja K. Formulation and evaluation of voricanazole loaded nanosponges for oral and topical delivery. Int. J Drug Dev Res 2013; 5(1): 55-69.

[16] ICH harmonised tripartite guideline validation of analytical procedures: text and methodology Q2(R1) Available from: http://www.ich.org/fileadmin/Public_Web_Site/ICH_Products/Guidelines/Quality/Q2_R1/Step4/Q2_R1_Guideline.pdf

[17] Ulrich M. Conducting stability studies- recent changes to climatic zone IV. Life Sci Tech Bull 2009; (13): 1-4.

[18] Jagdale S, Kurhe P, Kuchekar B, Chabukswar A. Application of design of experiments to optimizing novel gastroretentive drug delivery of simvastatin. Curr Drug Deliv 2013; 10(5): 527-41. [http://dx.doi.org/10.2174/1567201811310050004] [PMID: 23607639]

[19] Rao C, Ramadevi K, Soujanya V. Formulation and evaluation of floating matrix tablets of ramipril using peanut husk powder. Int J Pharm Dev Tech 2013; 3(2): 72-9.

[20] Jagdale SC, Kamble SB, Kuchekar BS, Chabukswar AR. Development and optimization of troxipide floating delivery for treatment of peptic ulcer. Curr Drug Ther 2014; 9(2): 83-92.

[http://dx.doi.org/10.2174/1574885508666131217003926]

[21] Jagdale SC, Agavekar AJ, Pandya SV, Kuchekar BS, Chabukswar AR. Formulation and evaluation of gastroretentive drug delivery system of propranolol hydrochloride. AAPS PharmSciTech 2009; 10(3): 1071-9. [http://dx.doi.org/10.1208/s12249-009-9300-8] [PMID: 19672719]

[22] International Ethical Guidelines for Biomedical Research Involving Human subjects, Council for International organizations of Medical Sciences in Collaboration with the World Health Organization In: Geneva 2002. Available from: http://www.cioms.ch/ publications/layout guide2002.pdf

[23] Shirsand SB, Sarasija S, Para MS, Swamy PV. Design of fast disintegrating tablets of Prochlorperazine maleate by effervescent method. Ind J Pharm Sci 2009; 71(4): 447-51.

[24] U.S. Pharmacopeia National Formulary 2011: USP 34 NF 29 (United States Pharmacopeia/National Formulary), by U.S. Pharmacopeial Convention, Pck Sup ed, 2011.

[25] Margareth RC, Ralmar L, May A. Simulated biological fluids with possible application in dissolution testing. United State Pharmacopoeia 2011; pp. 17-8.

[26] Gupta P, Kumar M, Sachan N. An overview on polymethacrylate polymers in gastroretentive dosage forms. Open Pharm Sci J 2015; 9: 31-42. [http://dx.doi.org/10.2174/1874844901502010031]

[27] Mitsuyuki M, Kazuhiko A, Chizuko N, Masahiro N. Delayed-release tablets using hydroxyethylcellulose as a gel-forming matrix. Int J Pharm 1996; 138(2): 225-35 [http://dx.doi.org/10.1016/0378-5173(96)80001-P]

[28] Costa P, Sousa Lobo JM. Modeling and comparison of dissolution profiles. Eur J Pharm Sci 2001; 13(2): $123-33$. [http://dx.doi.org/10.1016/S0928-0987(01)00095-1] [PMID: 11297896]

(C) Jagdale and Randhave; Licensee Bentham Open.

This is an open access article licensed under the terms of the Creative Commons Attribution-Non-Commercial 4.0 International Public License (CC BY-NC 4.0) (https://creativecommons.org/licenses/by-nc/4.0/legalcode), which permits unrestricted, non-commercial use, distribution and reproduction in any medium, provided the work is properly cited. 